\title{
Dossiê
}

TRIBUNAL DO SANTO OFÍCIO PORTUGUÊS, 200 ANOS APÓS EXTINÇÃO: HISTÓRIA E HISTORIOGRAFIA

\section{SODOMIA FAEMINARUM: A INQUISIÇÃO E A ALFORRIA DO LESBIANISMO NO MUNDO PORTUGUÊS, 1646*}

\author{
INQUISITION AND THE MANUMISSION OF LESBIANISM IN THE PORTUGUESE \\ WORLD, 1646
}

$\operatorname{Luiz}_{\text {Mott }}^{* *}$

\begin{abstract}
RESUMO
A história da homossexualidade em Portugal confirma a mesma tendência observada no resto do mundo: o lesbianismo sempre foi muito menos perseguido do que a homossexualidade masculina. Nesse artigo analisamos um documento inédito de 1646, onde os Inquisidores de Lisboa, após consulta do Tribunal do Santo Oficio de Goa, discutem detalbadamente, baseados em diversificada bibliografia, a opinião dos principais teólogos morais da cristandade sobre o tema. Apesar de manifestarem posicionamentos antagônicos, prevaleceu a exclusão da "sodomia faeminarum" da condição de "sodomia perfeita", deixando a partir de então o lesbianismo de ser crime punivel com a fogueira, passando sua perseguição, mais branda, à justiça secular.
\end{abstract}

PALAVRAS-CHAVE Inquisição. Lesbianismo. Sodomia. Descriminalização.

\begin{abstract}
The history of homosexuality in Portugal confirms the trend observed in the rest of the world: lesbianism has always been much less persecuted than male homosexuality. In this article we analyze an unpublished document from 1646, in which the Lisbon Inquisitors, after consulting the Court of the Holy Office of Goa, and based on diverse bibliography, discussed in detail the opinion of the main moral theologians from Christendom on the subject. Despite antagonistic positions, the exclusion of "sodomy faeminarum" from the condition of "perfect sodomy" prevailed, thus chaning lesbianism's status from a crime punishable by burning to a milder matter, settled by secular justice.
\end{abstract}

KEY-WORDS: Inquisition. Lesbianism. Sodomy. Decriminalization.

\footnotetext{
* Este artigo, em versão aqui ampliada, foi apresentado originalmente na International Conference on Lesbian and Gay History, em Toronto, Canadá, em julho 1985 (MOTT, 1985). Usamos indistintamente o latinismo "sodomia faeminarum e foeminarum".

** Professor Titular aposentado da Universidade Federal da Bahia (UFBA). Doutorado em Antropologia pela Universidade Estadual de Campinas (Unicamp). Pós-doutorado no Arquivo Nacional da Torre do Tombo, Portugal. Email: luizmott@yahoo.com.br
} 


\section{A UMA DAMA QUE MACHEAVA OUTRAS MULHERES}

Pesquisando a história dos sodomitas no Arquivo Nacional da Torre do Tombo de Lisboa, encontrei um documento crucial para o resgate da história da lesbianidade no mundo luso-indobrasileiro. A Inquisição Portuguesa após mais de um século de existência, em 1646, decide não considerar o tribadismo como sodomia perfeita, escapando as lésbicas da fogueira, mantendo-se, porém, a condição de pecado mortal merecedor do fogo do inferno e de sanções previstas nas Ordenações do Reino. Essa alforria parcial da então chamada sodomia foeminarum, sodomia das mulheres, confirma tendência universal da muito menor perseguição ao homoerotismo feminino do que ao masculino, evidenciada também na incendiária história da Inquisição Portuguesa, que não registra nenhum caso documentado de lésbica condenada à fogueira.

O objetivo desse trabalho é divulgar e discutir dois documentos inéditos que trazem importantes luzes para os estudos diacrônicos da lesbianidade, analisando diferentes opiniões de inquisidores, baseadas em teólogos, moralistas e juristas sobre a prática feminina desse "amor que não ousava dizer o nome".

Como hors-d'oeuvre, divulgamos belo e pouco conhecido soneto do príncipe dos poetas baianos, Gregório de Matos (1636-1695), ele próprio denunciado à Inquisição por blasfemar que "Jesus era sodomita". ${ }^{1}$ Esse poema, uma verdadeira delicatessen para o estudo literário do lesbianismo, intitulado "Nise: A uma dama que macheava outras mulheres", representa a primeira página literária produzida nas Américas onde se descreve a performance desenvolta de uma lésbica "que tomava todas as mulheres" e ousou resistir às investidas do poeta:

Foste tão presta em matar-me, Nise, que não sei dizer-te, Se em mim foi primeiro o ver-te, do que em ti o contentar-me Sendo força o namorar-me, com tal pressa houve de ser, Que importando-me aprender a querer, e namorar, Por mais me não dilatar namorei-me sem saber.

A saber como te amara, menos mal me acontecera, Pois se mais te compreendera, tanto menos te adorara: A vista nunca repara, no que dentro d'alma jaz, E, pois, tão louca te traz que só por Damas suspiras, Não te amara, se tu viras, esse vício a que te vás.

Se por Damas me aborreces absorta em suas belezas, A tua como a desprezas, se é maior que as que apeteces? Se a ti mesma te quisesses, querendo, o que a mim me praz, Seria eu contente assaz, mas como serei contente,

Se por mulheres se sente, que a homem nenhum te dás?

Que rendidos homens queres, que por amores te tomem? Se és mulher não para homem, e és homem para mulheres? Qual homem, ó Nise, inferes, que possa senão eu ter

\footnotetext{
1 Arquivo Nacional da Torre do Tombo, Tribunal do Santo Ofício, Inquisição de Lisboa [Doravante ANTT, TSO, IL.], Cadernos do Promotor, n. 58, 1464-1475; Peres (1987); Mott (2010).
} 
Valor para te querer? Se por amor nem por arte

De nenhum deixas tomar-te, e tomas toda a mulher!"

(MATOS, 1969, p. 1361)

"Nise" com certeza é um onomástico fictício, inspirado na mitologia grego-romana; significa “pura, casta”, identificando uma das Nereides n’Os Lusiadas, de Luís de Camões, usado igualmente por outros poetas do período colonial sem conotação lesbiana. Discreto, o Boca do Inferno preferiu manter no armário a verdadeira identidade desta esbelta mulher que macheava outras damas: tal cuidado certamente foi estratagema para não afastar ipso facto de seu virtual campo erótico a bela moçoila, pois em outras ocasiões, o poeta proclamou em alto e bom tom os nomes completos dos sodomitas de ambos os sexos, inclusive do próprio Governador da Bahia, Câmara Coutinho, esculhambando notadamente as mulheres negras e mulatas envolvidas em atos de luxúria:

\footnotetext{
Maribonda, minha ingrata, tão pesada ali se viu, Que desmaiada caiu, sobre Luiza Sapata: Viu-se uma e outra mulata em forma de sodomia, E como na casa havia tal grita e tal confusão, Não se advertiu por então o ferrão que lhe metia... (MATOS, 1969, p. 625)
}

Segundo o poeta, Nise era mulher muito bela, uma dama, isto é, "senhora nobre, de qualidade". Era dada ao vício - "defeito moral, tendência para o mal, erro" - de suspirar por outras damas. Ousada, chegava a tomar "toda a mulher". Desenvoltura que nos faz lembrar da mais aventureira e destemida safista açoitada publicamente durante a $1^{a}$ Visitação do Santo Ofício à Bahia, em 1592, Felipa de Sousa, infamada de namorar e de ter roçado com "muitas mulheres e moças, altas e baixas e também dentro de um convento". ${ }^{2}$

A grande beleza de Nise descarta a hipótese atabalhoada de alguns psicanalistas, como Flávio Gikovate, que atribuíram a prática da homossexualidade a pessoas geralmente feias, rejeitadas por pretendentes do sexo oposto e que encontrariam no abjeto homoerotismo a única saída para seus impulsos heteroeróticos fracassados (MOTT, 1987). Aliás, a beleza física e extrema sensualidade eram condições sine qua non para a admissão das noviças aos Templos de Vesta, uma curiosa e secretíssima instituição formada exclusivamente por lésbicas que existiu na França oitocentista: "A candidata devia apresentar-se nua perante as associadas reunidas e submeter-se a um exame completo para que se verificassem quantos dos trinta encantos femininos descritos numa velha ode francesa possuiria realmente" (CAPRIO, 1968, p. 26).

Nise parece ser uma das poucas lésbicas de nosso período colonial que vivia celibatária -"a nenhum homem te dás" -, pois grande parte das denunciadas na Inquisição eram casadas ou viúvas. O casamento no antigo regime era uma exigência social tão forte que a vida de um/a solteiro/a se tornava verdadeiro suplício, quando não inviável: a rígida divisão sexual do trabalho impunha o matrimônio como solução necessária para ambos os sexos mesmo antes de chegar à idade adulta, sobretudo para o

2 ANTT, TSO, IL, Processo 1267 apud Mott (1999). 
"sexo frágil". As Constituições Primeiras do Arcebispado da Babia (\$267) autorizavam o matrimônio das meninas a partir dos 12 anos e aos 14 o dos meninos, bastando sete anos de idade para ambos os sexos poderem realizar o chamado "desposório de futuro". Para alguns jovens e adultos, como ocorre ainda hoje em dia, casar-se era a maneira ideal de disfarçar uma homossexualidade clandestina (MOT'T, 2006).

Ainda digna de nota é a concepção maniqueísta do poeta em relação aos amores lésbicos: o não gostar de homens implicaria que a bela Nise tivesse ela própria de agir como se fosse um conquistador masculino: "és homem para mulheres". A maioria dos heterossexuais imagina que os/as amantes do mesmo sexo seguem mecanicamente o seu mesmo esquema relacional binário, agindo os machos como sexo forte e as fêmeas, como sexo frágil, "agente e paciente", no linguajar dos Inquisidores. Muito embora algumas homossexuais copiem o modelo hétero da bipolaridade macho-fêmea, ativa-passiva, lady-sapatão, despontando nos últimos anos nova categoria sexológica, os "homens-transexuais", tal normatividade não é absoluta, nem tampouco a aparência delicada de uma lésbica implica que ela há de ser passiva, ou que uma das parceiras tenha de ser varonil e ativar a relação. A formosa Nise escandalizava o Boca do Inferno exatamente por ser muito feminina e, não obstante, "machear" outras filhas de Eva. Veremos adiante o caso documentado de outra lésbica da Bahia que macheava outras mulheres, essa sim, assumida!

\section{MACHOAS DESEJOSAS DE CONO}

Segundo o pioneiro Asdrúbal Antônio d'Aguiar, o mais enciclopédico estudioso da homossexualidade em Portugal, autor do insuperável Evolução da pederastia e do lesbismo na Europa (1926), provavelmente desde o século XII que os Penitenciais de Angers e Fleury passaram a ser adotados também na Lusitânia, prescrevendo três anos de penitência para as mulheres convencidas em atos homoeróticos, sendo no primeiro ano obrigadas a jejuar apenas com pão e água, aumentando para sete anos de penitência em se tratando de freiras, dos quais, os dois primeiros anos deviam ser mantidos somente a pão e água. Salvo erro, seriam estes os mais antigos registros de castigos prescritos à sodomia praticada por mulheres na Ibéria, já então diferenciada da sodomia masculina e da cópula anal heterossexual (AGUIAR, 1926; PAYER, 1986, p. 138)).

Malgrado toda a perseguição e anátemas contra o nefando pecado de sodomia, o certo é que desde o século XIV encontramos na literatura galega referência a personagens lésbicas, dentre elas a mais famosa, uma tal de Mari'Mateu, a quem o trovador Afonso Anes do Cotom (1240) denunciava como concorrente na disputa da genitália feminina, então popularmente chamada de "cono", expressão persistente também na Bahia do século XVI como veremos mais adiante:

\footnotetext{
Mari’Mateu, Mari’Mateu, tão desejosa sois de cono, como eu! ${ }^{3}$
}

\footnotetext{
${ }^{3}$ Cancioneiro Português da Vaticana. Edição crítica por Teófilo Braga. Lisboa: Imprensa Nacional, 1878, canção 1115.
} 
Outra que ficou famosa na literatura dos cancioneiros portugueses por preferir "conos a caralhos" foi Dona Guiomar de Castro, cantada como sendo macho e amante de beijar e ir para a cama com outras damas:

$$
\begin{aligned}
& \text { Dois gostos podeis levar, } \\
& \text { senhora desta maneira, } \\
& \text { pois sabeis de tudo usar, } \\
& \text { ser macho para Guiomar } \\
& \text { e fêmea para Nogueira. } \\
& \text { E por isso não vos tacho, } \\
& \text { antes vos quero louvar, } \\
& \text { nos trajos em vos acho, } \\
& \text { podereis vos emprenhar, } \\
& \text { outra mulher como macho. }
\end{aligned}
$$

Embora perceba-se certa tolerância do Cancioneiro Geral de Rezerende em referir-se a essa mulhermacho, aparentemente bissexual, sua intolerância manifesta-se sem rodeios noutro poema, antecipando terreno para a justificação ideológica da lesbofobia institucional, quando, dois séculos depois, instalamse os Tribunais do Santo Ofício em diversas terras lusitanas:

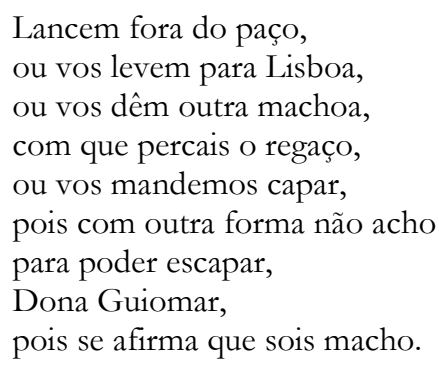

A versatilidade sexual dessa Dona Guiomar é o que mais melindra e desconcerta os defensores da rígida moral-sexual judaico-cristã que, no seu conhecido e cruel maniqueísmo heterossexista, repudia e demoniza não só o pseudo-hermafroditismo físico, mas também a bissexualidade psicossocial, já que a heteronormatividade e o binarismo sexual e de gênero teriam sido determinados pelo próprio Criador: "E Deus os fez macho e fêmea!" (Genesis, 1:27). Daí a sugestão primária do Trovador, no final dessa cantiga: "Ficai fêmea ou macho", mandando que se cortasse seu imaginado falo, ou tapasse seu abominável vaso dianteiro:

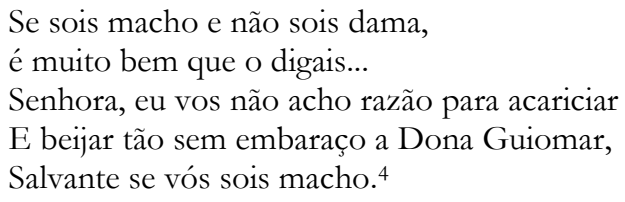

E não se pense que era apenas no Reino, no tempo dos trovadores, que mulheres macheavam outras mulheres e se declaravam publicamente "desejosas de cono", chegando inclusive a utilizar

${ }^{4}$ Monteiro (1922, p. 131); Brandão (2010). 
brinquedos eróticos. Em 1592, na Primeira Visitação do Santo Ofício à Bahia, é denunciada à Mesa Inquisitorial a negra forra Francisca Luís, 40 anos, vendedeira, por ter dado um recado a uma mulher solteira chamada "A do veludo", dizendo "que não a agravasse e o que houvesse mister, que tho mandasse pedir que lho daria e não andasse com outrem, isto a mode de ciúmes, e de então até agora, é fama pública e geral que a dita Francisca Luiz dorme carnalmente com Isabel Antônia, mulher que não tem marido, que veio degredada do Porto por usar do pecado nefando com outras mulheres, e que tem o dito ajuntamento nefando com um instrumento coberto de veludo".

Em sua confissão, Francisca Luiz declara que, de fato, ambas moraram juntas e que praticaram "o dito pecado nefando algumas três vezes em diferentes dias, pondo-se uma em cima da outra e ajuntando seus corpos e vasos, e isto sem haver mediante outro nenhum instrumento exterior penetrante e não se lembra se teve cumprimento natural que as mulheres costumam ter, nem sabe se teve a dita cúmplice, porém já por este caso elas ambas foram presas nesta cidade pelo Juízo Eclesiástico e ela ré saiu condenada para que se saísse fora daqui, mas depois a deixaram ficar". Certamente atenuou suas culpas com medo do castigo pois era pública na Bahia que coabitaram longamente, sendo do público conhecimento que usavam sim um falo artificial revestido de veludo em suas relações homoeróticas, daí o apelido de Isabel Antônia, "A do veludo".

Essa referida prisão pelo Juízo Eclesiástico fora determinada provavelmente pelo bispo da Bahia, Dom Antônio Barreiro. No traslado de testemunhas que depuseram nesse juízo, apenso ao processo inquisitorial, onze folhas de difícil leitura, lê-se que Isabel Antônia teve uma conturbada relação com Francisca Luiz, causando grande escândalo na pequenina capital da América Portuguesa, incluindo gritaria, cenas públicas de violência física e ciúme, "numa das quais, Francisca, ao saber que Isabel tinha saído com um homem, dirigiu-se Francisca Luís a ela aos brados de: velhaca! Quantos beijos dás ao seu coxo (amante) e abraços não dás a mim um! Não sabes que quero mais a um cono que a quantos caralhos aqui há! Disse tudo isto aos berros, pegando-a pelos cabelos, trazendo-a porta a dentro com açoites e bofetões à vista dos vizinhos." " ${ }^{5}$ Lesbianidade tóxica... A questão dos falos artificiais de vidro ou madeira utilizados entre mulheres em suas somitagarias será retomado mais adiante, quando os Inquisidores discutem se tal uso implicaria ou não no crime de "sodomia perfeita".

\section{LEGISLAÇÃO CONTRA A SODOMIA FAEMINARUM}

Quanto à legislação especificamente portuguesa relativa ao lesbianismo, é a partir de 1499, nas Leis Extravagantes de D. Manuel, que se define claramente pela primeira vez: "a mulher que usa torpemente como homem, haverá a mesma pena que o homem que tal pecado com outro macho

\footnotetext{
5 ANTT, TSO, IL, Processo 13.787. Disponível em: https://digitarq.arquivos.pt/details?id=4510000. Agradeço ao Prof. Ronaldo Vainfas pela indicação deste documento.
} 
comete"; isto é, devia ser queimada, reduzida a pó, ter seus bens sequestrados, seus descendentes tornados inábeis para que "não ficasse delas memória". ${ }^{6}$

Inexplicavelmente, as Ordenações Afonsinas (1446) não fizeram qualquer referência ao lesbianismo; já as Ordenações Manuelinas (1512) equiparam a sodomia foeminarum à sodomia virorum: "Esta lei da sodomia queremos que também se entenda e haja lugar nas mulheres que este pecado umas com outras cometerem, assim como nos homens". ${ }^{7}$ As Ordenações Filipinas (1603) ratificam essa mesma inclusão e as penalidades anteriores. ${ }^{8}$

Além das Ordenações do Reino, os Regimentos do Santo Ofício da Inquisição legislaram contra o abominável pecado de sodomia cometido pelas pecadoras filhas de Eva. Os Regimentos de 1552, 1570 e 1613 são omissos ao lesbianismo, assim como as Bulas condenatórias da sodomia masculina de Pio IV (1559-1565) e de Gregório XIII (1572-1585) não mencionam explicitamente o gênero feminino (MOTT, 1988).

É só no Regimento de 1640, de D. Francisco de Castro, mais de um século após a instalação do Santo Tribunal da Fé na Lusitânia, que se afirma a primeira legislação inquisitorial reprimindo o tribadismo:

\begin{abstract}
Em caso que alguma mulher seja compreendida no crime de sodomia, há de ser castigada por ele no Santo Ofício, ouvirá sua sentença na Sala da Inquisição pelo grande escândalo e dano que pode resultar de se levarem a Auto Público semelhantes culpas, e será degredada para a Ilha do Príncipe, São Tomé e Angola. E quando se assentar que por algumas razões particulares convém ir ouvir sua sentença no Auto Público da Fé, será condenada em penas de açoites e no degredo que parecer para um dos ditos lugares. ${ }^{9}$
\end{abstract}

Neste caso em particular, entenda-se por "crime de sodomia" tanto as relações carnais entre mulheres quanto a cópula anal heterossexual, posto que ambas estavam compreendidas sob esta mesma rubrica e o texto regimental é genérico neste particular.

Apesar das ordenações régias e dos regimentos inquisitoriais ordenarem as mesmas draconianas penas contra as mulheres convencidas no nefando pecado de sodomia - jejum severo, açoites, degredo, até a pena de morte - estipulando-se inclusive prêmios pecuniários aos que as denunciassem, não obstante tamanha severidade só encontramos uma vaga notícia sobre mulheres tríbades publicamente punidas em Lisboa, segundo o relato do doutor em medicina Roderico de Castro, anterior a 1603 e, muito embora ele diga ter visto tal punição, não faz referência de que modo e qual dos tribunais, se o da Inquisição ou o do Rei, teria castigado esse "crime repugnante". ${ }^{10} \mathrm{Nem}$ nos registros inquisitoriais,

\footnotetext{
${ }^{6}$ REPERTÓRIO Geral ou Índice Alfabético das Leis Extravagantes do Reino de Portugal. Determinação de 20 de dezembro de 1499. Coimbra: Real Imprensa da Universidade, 1819.

7 Ordenações do senhor Rei D, Manuel, Coimbra, 1797, Livro V, Título XII, \$3.

8 Ordenaçôes e Leis do Reino de Portugal recopiladas por mandado del Rei D. Filipe o Primeiro, Coimbra, 1789, Livro V, Titulo $\$ 1 .$.

${ }^{9}$ Regimento do Santo Ofício da Inquisição dos Reinos de Portugal, ordenado por mandado do Ilustríssimo e Reverendíssimo Senhor Bispo D. Francisco de Castro, Lisboa, 1640, Titulo XXV, livro III, \$13; Regimento do Santo Oficio, 1774, título XXII, \$12.

10 "De duabus turcis thessalonicensisbus Amatus refert et nos Ulissiponae ob símile foedissimum scelus aliquot mulieres publice puniri vidimus, tribades dicuntur a Celio Aureliano, a Plauto subigatrices et Martial de Bassaa quandam inquit" (CASTRO, 1603, p. 6). Agradeço à Dra.Ligia Belini (UFBA) a indicação desse documento.
} 
nem da justiça civil, encontramos sequer uma mulher condenada à pena de morte por sodomia nem em Portugal nem em seus domínios da América, África e Índia.

São raras as referências a relações lésbicas encontradas nos milhares de processos e nos Cadernos e Repertórios do Nefando depositados na Torre do Tombo, relativos às inquisições de Lisboa, Évora, Coimbra e Goa. ${ }^{11}$ Salvo erro, o mais antigo registro data de 1570: Isabel Álvares, solteira, moradora na Vila do Conde, é denunciada na Visitação Geral entre Douro e Minho de cometer pelo espaço de cinco anos o pecado contra natura com outra mulher, se abraçando, beijando e "apalparem e meterem as mãos em as naturas uma da outra” (ABREU, 1980). Em 1574, sóror Maria do Espírito Santo, 24 anos, clarissa, rodeira no Mosteiro de Santa Marta de Lisboa, confessa que "estando em oração, sentiu o peito cheio de amor de Deus, tendo a inspiração de dar de mamar a sua filha espiritual Camila de Jesus”, 22 anos, e por seis meses consecutivos, por muitas vezes, as freirinhas ora abraçadas na cama, ora em locais apartados, repetiram inúmeras vezes tais lubricidades porno-místicas, consideradas pelos sacerdotes que examinaram o caso como "reprováveis e escandalosos enganos do demônio", sendo ambas condenadas a jejuar a pão e água toda sexta feira por três anos. ${ }^{12}$ Em 1659, é presa uma falsa vidente, Joana da Cruz, recolhida na Ordem Terceira de São Francisco de Lisboa, confessando que aos 12 anos uma moça com quem residia à mesma casa e que lhe fazia muitos favores, convidou-a a deitar-se de noite em sua cama, mostrando-lhe um instrumento com que dizia a haveria de brincar e folgar". ${ }^{13}$

Em terras brasílicas, a presença de lésbicas nativas é registrada já pelos primeiros cronistas: o jesuíta Pero Correia (1551), um dos fundadores de São Paulo de Piratininga, relatou: "Há entre os Tupinambá muitas mulheres que assim nas armas como em todas as outras coisas seguem oficio de homens, e têm outras mulheres com quem são casadas. A maior injúria que lhes podem fazer é chamálas de mulheres" (CORREIA, 1940). Gandavo (1576) confirma:

\footnotetext{
Algumas índias há entre os Tupinambá que não conhecem homem algum de nenhuma qualidade, nem o consentirão, ainda que por isso as matem. Elas deixam todo o exercício de mulheres e imitam os homens e seguem seus ofícios como se não fossem fêmeas. Trazem os cabelos cortados, da mesma maneira que os machos, e vão à guerra com os seus arcos e flechas, e à caça, perseverando sempre na companhia dos homens. Cada uma tem mulher que a serve, e que lhe faz de comer e com quem diz que é casada. E assim se comunicam como marido e mulher (GANDAVO, 1964, p. 57-91).
}

Tão institucionalizada era a inversão lesbiana entre nossas tribos litorâneas que no Vocabulário da Lingua Brasilica (1621) registravam os jesuítas - certamente a contragosto - um termo específico de como eram designadas as tais mulheres guerreiras entre os Tupinambá: çacoaimbeguira, isto é, "machão que não conhece homem e tem mulher e fala e peleja como homem.” (PACHECO, 1934)

Data de 1580 a primeira referência a uma lésbica branca na América Portuguesa: Isabel Antônia,

\footnotetext{
11 Braga (1996, p. 87-90); Soyer (2012).

12 ANTT, IL, Proc.3185. Também na Itália, no século seguinte, a abadessa do convento das Teatinas de Brescia, Benedetta Carlini de Vellano (1591-1661), foi condenada à prisão perpétua por incorporar a performance do Anjo Splenditello, dando seu peito a mamar e praticando atos homoeróticos com outra freira durante anos consecutivos (BROWN, 1987).

13 ANTT, IL, Proc. 557. Cf. Braga (2011). Sobre a lesbianidade em Espanha, cf. Velasco (2011).
} 
natural do Porto, apelidada "a do veludo" e referida como "mulher sem marido", fora degredada do reino para Salvador, "por usar do pecado nefando com outras mulheres". Denunciada e condenada por tal pecado abominável no Juízo Eclesiástico da Bahia, pelo Bispo Dom Antônio Barreiro, consta em seu sumário de culpas que ela tivera uma conturbada relação com Francisca Luiz, negra, causando grande escândalo na pequenina capital da América Portuguesa, com cenas públicas de violência física e ciúme, "numa das quais, Francisca, ao saber que Isabel Antônia tinha saído com um homem, dirigiu-se a ela aos brados de: 'Velhaca! Quantos beijos dás ao seu coxo (amante) e abraços não dás a mim um! Não sabes que quero mais a um cono que a quantos caralhos aqui há!' Disse tudo isto aos berros, pegando-a pelos cabelos, trazendo-a porta a dentro com açoites e bofetões à vista dos vizinhos." Conta que Isabel Antônia morreu antes da chegada do Visitador à Bahia. Era fama pública na Bahia que usava um falo artificial revestido de veludo em suas relações homoeróticas, daí o apelido "a do veludo". ${ }^{14}$ Anos mais tarde, já no encerramento da Primeira Visitação à Bahia, (1592), a negra Francisca Luiz é chamada perante o Visitador e diz ser natural do Porto, moradora em Salvador, 40 anos, filha de Luiz, cativo do Chantre do Porto, que não conheceu sua mãe, negra forra, abandonada pelo marido Domingos Soares, pardo, remendão; disse que "sabe ler pela cartilha". Foi denunciada por uma vizinha, relatando que há oito anos passados, viu Francisca Luiz dar um recado a uma mulher solteira chamada "a do veludo" dizendo "que não a agravasse e que o que houvesse mister que lho mandasse pedir que lho daria e não andasse com outrem, isto a mode de ciúmes, e de então até agora, sempre ela denunciante vê ser fama pública e geral que a dita Francisca Luiz dorme carnalmente com Isabel Antônia e que tem o dito ajuntamento nefando com um instrumento coberto de veludo".

Francisca confessou que há quinze anos passados (1577) na cidade do Porto, "morou de portas a dentro duas vezes com Maria Álvares, tecedeira, mulher que em casa não tinha marido" e que há 13 anos está na Bahia, tendo amizade nesta cidade com Isabel Antônia, "mulher que não tem marido, que diziam que veio degredada do Porto por usar do pecado nefando com outras mulheres, e por ela ser sua natural, ela ré se agasalhou em sua casa um mês, pouco mais ou menos, no qual tempo pecou com ela o dito pecado nefando algumas três vezes em diferentes dias, pondo-se uma em cima da outra e ajuntando seus corpos e vasos, e isto sem haver mediante outro nenhum instrumento exterior penetrante e não se lembra se teve cumprimento natural que as mulheres costumam ter, nem sabe se teve a dita cúmplice, porém já por este caso elas ambas foram presas nesta cidade pelo Juízo Eclesiástico e ela ré saiu condenada para que se saísse fora daqui, mas depois a deixaram ficar e que isto é o que se lembra". Negou categoricamente ter mandado qualquer recado enciumado a Isabel Antônia, ratificando que "nunca mais, nem antes nem depois em todo o tempo de sua vida se lembra que pecou o tal pecado nefando". Foi condenada a pagar 10 cruzados para as despesas do Santo Ofício e obrigada a se confessar e jejuar nas principais festas eclesiásticas. ${ }^{15}$

${ }^{14}$ ANTT, IL, Proc.13.787; Cf. Vainfas (1987).

15 ANTT, IL, Proc.13.787; Mott (1999). 
Nas Visitações do Santo Oficio ao Brasil - entre 1591-1595 - 29 mulheres, predominando jovens, confessam e/ou são denunciadas pelo pecado contra natura, conforme revelou a historiadora Lígia Bellini na obra A coisa obscura: mulher, sodomia e Inquisição no Brasil colonial (BELLINI, 1989). ${ }^{16}$ Destas, a que recebeu maior castigo foi Felipa de Sousa, 35 anos, que, pelo ano de 1583, em Salvador, "enamorou e se afeiçoou" por Maria Peralta, solteira, moça que ainda não tinha conhecido homem, 18 anos; dormindo na mesma cama, de porta fechada, pôs-se sobre a moça ajuntando seus vasos dianteiros e deleitando-se, "mas não cumpriu desta primeira vez da maneira que interiormente as mulheres costumam cumprir estando no ato carnal". Anos depois, após enviar algumas cartas e recados de amor a Paula de Siqueira, mulher do contador Antônio de Faria, um dia lhe deu um abraço e beijo "com tenção desonesta" e no dia da festa de Nossa Senhora do Ó, ficaram juntas ambas na igreja de São Francisco, e depois Paula de Siqueira levou-a para sua casa e, antes do jantar, se deitaram na cama, a dona da casa pondo-se em cima, ajuntando seus vasos, mas só Paula de Siqueira "cumpriu", conforme depois declarou. Após o jantar e terem bebido bastante vinho, novamente Paula a convidou e ajuntaram suas naturas, cumprindo três vezes enquanto ela, ré, não chegou ao orgasmo. Nunca mais repetiram tais encontros nefandos.

Com a mulher de um ferreiro acorcovado, Ana Fiel, sua vizinha, Felipa trocou um abraço e beijo em afeição desonesta, "e o dito abraço e beijo deram por cima de uma parede entre os seus quintais". Arrematou sua confissão declarando que "todos esses ajuntamentos lhe causaram grande amor e afeição carnal, com que da vista se afeiçoava com as ditas mulheres..."

Aos 24 de janeiro de 1592, então ré do Santo Ofício, a afoita e infeliz Felipa de Sousa teve a maior dor e humilhação em toda sua vida: retirada da Casa da Visitação, no Terreiro de Jesus, o Ouvidor da Capitania levou-a até a Sé da Bahia, onde, vestida simplesmente com uma túnica branca, descalça, com uma vela na mão, de frente à Mesa Inquisitorial e de algumas autoridades religiosas, ouviu sua ignóbil sentença. Em seguida foi açoitada publicamente pelas principais ruas do centro de Salvador, enquanto o Ouvidor lia o pregão: "Justiça que manda fazer a Mesa da Santa Inquisição: manda açoitar esta mulher por fazer muitas vezes o pecado nefando de sodomia com mulheres, useira e costumeira a namorar mulheres. E que seja degredada para todo o sempre para fora desta capitania”. ${ }^{17}$ Onde foi cumprir o seu degredo, não informam os documentos. Felipa de Sousa é a mais ousada, persistente e castigada de todas as lésbicas da América Portuguesa, razão pela qual seu nome foi atribuído ao principal prêmio internacional de Direitos Humanos de Lésbicas e Gays, o chamado "Felipa de Sousa Award", conferido pela International Lesbian and Gay Human Rights Comission, de S. Francisco, Estados Unidos.

\title{
IV INQUISIDORES SE POSICIONAM SOBRE A SODOMIA FAEMINARUM
}

\author{
${ }^{16}$ Cf. Napolitano (2004a; 2004b). \\ ${ }^{17}$ ANTT, TSO, IL, Proc. 1267. \\ Pol. Hist. Soc., Vitória da Conquista, v. 20, n. 1, p. 45-66, jan.-jun. 2021. ISSN 2236-8094
}


Se as leis - tanto civis, quanto religiosas - eram severas na condenação dos amores lesbianos, como explicar a indulgência inquisitorial às mulheres culpadas no pecado nefando durante o século XVI e o quase desaparecimento da repressão a este crime abominável no rol das mulheres processadas pelo Santo Ofício a partir do século XVII?

A documentação sinaliza que não havia consenso entre os Inquisidores se as relações sexuais entre mulheres constituíam sodomia perfeita; daí titubearem se a pena máxima da fogueira também deveria ser aplicada às filhas de Eva, como prescreviam as Ordenações do Reino, já que os Regimentos do Santo Ofício não eram explícitos sobre esse particular. As dúvidas pairavam no ar, tanto que duas cartas são enviadas da Índia, do Santo Oficio de Goa, a primeira, datada de 28 de dezembro de 1644 e a outra de 28 de janeiro de 1645, por meio das quais os Inquisidores d'além mar consultam o Conselho Geral de Lisboa, órgão supremo centralizador de todos os Tribunais do Reino e Ultramar, "como proceder contra as mulheres que umas com as outras tiverem cópula e atos sodomíticos, sendo íncubas ou súcubas, agentes ut viri (como homens), com instrumento ou sem ele, per vas anterius aut posterius" (pelo vaso anterior ou posterior). ${ }^{18}$ Quer dizer: apesar do Regimento prescrever açoites e degredo às mulheres "compreendidas no crime de sodomia", a dúvida dos Inquisidores da Índia obrigam-nos a conjecturar que o entendimento do espírito da lei referia-se precipuamente às mulheres praticantes da cópula anal heterossexual ${ }^{19}$, malgrado haver precedentes, na jurisprudência inquisitorial, de mulheres processadas, mas não queimadas, pela prática de "torpezas ad invicem", isto é, umas com as outras.

Tal documento, inédito até quando o descobrimos e divulgamos, em 1985, no International Conference on Lesbian and Gay History,em Toronto (MOTT, 1985), encontra-se no obra Tribunalem Perfectum (sive) Comentaria ad Regimen Sancti Officii Regni Portugaliae, Conselho Geral 123, Manuscritos da Livraria do Santo Ofício, n.1358-1359, de Joannis Alvares, Inquisidor, Lisboa, Tomo I, Gloss.38, trazendo como título "Contra os culpados no crime de sodomia".

Na Dubitatio II lê-se: "Se pode o Santo Ofício em virtude dos Breves Apostólicos e Provisão do Cardeal D. Henrique, proceder contra as mulheres que umas com as outras tiverem cópula e atos sodomíticos, sendo íncubas e súcubas agentes ut viri com instrumento ou sem ele per vas interius aut posterius." Seguem três premissas:

$1^{\text {a: }}$ as Bulas de Pio V e Gregório XIII não condenam abusos com animais de espécie diversa, nem sodomia com sexos opostos, portanto as Bulas não devem englobar também tal espécie de torpeza;

$2^{a}$ : as Bulas referem-se claramente ao vaso posterior;

\footnotetext{
18 Biblioteca Nacional de Lisboa, Seção de Reservados, Códice 869, fl.361-364; Arquivo Nacional da Torre do Tombo, Manuscritos da Livraria, 1358-1359, Tribunale Perfectum (sive) Commentaria ad Regimem Sencti Officii Regni Portugaliae.

${ }_{19}$ Processos de mulheres inculpadas pela prática da cópula anal ou sodomia imperfeita: ANTT, TSO, IL, Proc. 1186 (Maria Machada, Lisboa 1621, prostituta, 26 anos); ANTT, IL, Proc. 1942 (Catarina Ligeira, Lisboa, 1630, viúva).
} 
$3^{\text {a: }}$ mesmo a cópula de homem com mulher pelo vas posterius não é sodomia perfeita apesar de horrível pecado. ${ }^{20}$

Passados 15 meses da primeira consulta proveniente da Inquisição de Goa, aos 22 de março de 1646, quatro inquisidores do Tribunal do Santo Ofício de Évora, secundados por três deputados, dão suas opiniões sobre essa melindrosa questão, prevalecendo no final a decisão de se manter a tradição inquisitorial de excluir o lesbianismo da categoria de sodomia perfeita, devendo-se consultar a Sé Apostólica de como se proceder nesse particular. Todos os pareceristas ostentam nobilíssimo curriculum e citam erudita bibliografia para justificar seus alvitres.

O primeiro a se manifestar foi o Inquisidor Álvaro Soares de Castro, então titular do Tribunal de Évora; de nobre cepa lusitana, começara sua carreira eclesiástica como cônego da Sé de Lisboa, foi investido em 1641 ao tribunal eborense, passando para o de Coimbra em 1654 e Lisboa em 1657, tornando-se membro do Conselho Geral em 1660; bispo eleito do Brasil, referido na Pedatura Lusitana como "grande sogeito". ${ }^{21}$

Pareceu ao inquisidor Álvaro Soares de Castro e ao Deputado Sebastião da Fonseca que fazendo-se pelas mulheres os ditos atos medio instrumento ad effundendum semen intra vas posterius seu anterius (por meio de instrumento para derramar semente dentro do vaso posterior ou anterior) pertence ao conhecimento do Santo Oficio porque não há dúvida que nele non servatur debitus sexus (não sendo observa o sexo devido) e se comete per vas (pelo vaso) não natural por parte do agente e por onde infundindo sêmen dentro do vaso posterior por aquele modo fica sendo própria, perfeita e consumada sodomia e não derramando sêmen, ao mesmo fica nos termos de conatus (tentativa) próximos na opinião mais comum dos doutores que afirmam não ser própria e perfeita sodomia sem efusão de semente dentro do vaso e para efeito de se castigar com a pena ordinária pelas quais razões cometendo-se geralmente ao Santo Ofício nos ditos breves apostólicos, se ficam compreendendo os tais atos como verdadeira espécie desta, o que não há lugar fazendo-se sola fricatione (somente frição) sem meio de instrumento porque ainda que sem ele, queriam alguns doutores que se pode derramar a mulher semente dentro do vaso da súcuba, contudo, é necessário também penetração, quando não pode haver, faltando o dito instrumento, como também havendo, sendo incapaz de por ele derramar semente, nos quais casos, não podem os tais atos exceder a espécie de molices (masturbação), assim na própria natureza do ato como também na intenção dos agentes, dos quais o Santo Ofício não toma conhecimento por não ser propriamente crime de sodomia que lhe foi cometido.

Merece um comentário a opinião do inquisidor Álvaro Soares de Castro: seu apego à definição estrita da sodomia, onde só se consubstancia a perfeição do crime se houver seminação dentro do ânus, remete-nos à concepção antiga da fisiologia sexual feminina, que acreditava ser possível também às mulheres ejacular. ${ }^{22}$ Distancia-se, porém, de destacados teólogos antigos, que postulavam a pena de

\footnotetext{
${ }^{20}$ Tribunalem Perfectum, sive Comentaria ad regimem Sancti Officii Regni Portugaliae. Manuscritos da Livraria, Joannis Alvares Soares, Inquisidor de Lisboa, 2 tomos, Tomo I, Gloss. 38, Contra os culpados no crime de sodomia, 2 dubitatio; Biblioteca Nacional de Lisboa, Correspondência da Inquisişão de Évora e Goa ao Conselho Geral, 1644-1646, fl.361-364; Código de referência on line: PT/TT/TSO-CG/035/0123 (conteúdo ainda não acessível).

${ }^{21}$ MORAIS, Cristóvão Alão (1632-1693). Pedatura Lusitana: Nobiliário de famílias de Portugal. Porto: Livraria Fernando Machado, 1943-1948.

22 COLOMBO, Realdo (1516-1559). Realdi Columbi Cremonensis, in almo Gymasio Romano Anatomici celeberrimi, De re anatomica, libri XV. Venetiis: Ex Typographia Nicolai Beuilacquae, 1559.; Cf. De Graaf (1668); Park (1997).
} 
morte apenas em havendo a utilização de instrumento penetrante "de vidro, madeira, couro, de qualquer outra matéria" 23 , enfatizando que só mesmo a seminação no vaso posterior é passível de condenação.

O segundo parecer traz a assinatura do Inquisidor Manuel de Magalhães de Menezes, que iniciou sua distinguida carreira eclesiástica como Arcediago da Catedral de Évora e, posteriormente, Inquisidor no Tribunal dessa mesma cidade ${ }^{24}$, nomeado em 1654 Inquisidor da Mesa de Lisboa e deputado do Conselho do Santo Ofício, em 1660. É o mais liberal dos pareceristas, escorando-se em seu pronunciamento tão somente no casuísmo processualístico da Inquisição, protelando-se sua deliberação: defende que só pertence ao Santo Ofício o conhecimento dos atos cometidos "médio instrumento per vas preposterum et non per vas anterius (através de instrumento pelo vaso traseiro e não pelo vaso dianteiro), por ser natural.

Eis seu parecer na íntegra, cuja redação é, contudo, mais trôpega que a dos demais embatinados:

Ao inquisidor Manuel de Magalhães e deputados Manuel do Valle e João Estaço, pareceu que somente pertenciam ao Santo Oficio os ditos atos cometendo-se por meio de instrumento pelo vaso posterior, o qual era somente o ordinário por onde se comete o crime de sodomia e não pelo vaso dianteiro, por este ser natural e incapaz de por ele cometer o dito crime de sodomia e só então fica nos termos de molice e que bastava ser o instrumento capaz de por ele, por fora ou por dentro, se comunicar semente do agente no dito vaso posterior, e que de ordinário se presumia que assim acontece. E, sobretudo, que este caso é gravíssimo, no qual se trata de tomar jurisdição ao Ordinário que nele lhe compete e de os réus neles compreendidos ficarem sujeitos a novos modos de proceder e maiores penas que no juízo dos Ordinários não padecem. E, outrossim, em razão da jurisdição do Santo Oficio carregando-a de novo com o penoso conhecimento destas torpezas e por conseguinte que pareça necessário dar-se maior tempo para se considerar essa matéria.

O Inquisidor Mateus Homem de Leitão é o terceiro a opinar: além de ser mais erudito que seus pares, é o mais explícito nos detalhes das performances sexuais lesbianas. Referido por seus contemporâneos como "vir acutissimus et doctissimus" (homem sábio e douto), doutorou-se em Direito Canônico pela Universidade de Coimbra, onde integrou o Colégio Doutoral, ocupando a função de lente de Prima na Faculdade de Cânones, mais tarde, Desembargador na Relação Eclesiástica de Braga. Familiar do Santo Ofício, Promotor, Deputado da Inquisição de Coimbra, torna-se Inquisidor em Évora em 1646 e, em Coimbra, em 1649. Terminou sua carreira de jurista, como era habitual, no Desembargo do Paço. Publicou De jure Lusitano in tres tratactus, em 1645, e De Conscientia veras et singularis observatio, em 1652.

E ao inquisidor Mateus Homem Leitão (pareceu) que de nenhum dos casos da proposta pertencia ao conhecimento do Santo Oficio porque ainda que os doutores digam que nos casos referidos e outros semelhantes se cometa a verdadeira sodomia, contudo, o Santo Oficio não conhece senão da propriíssima, a qual somente acontece quando membrum virile mittitur in vas preposterum (membro viril é metido no vaso posterior) e se o instrumento ou membro ficto bastara para verdadeira sodomia, também o fora e reconheceria o Santo Oficio quando o vaso fora ficto, por exemplo, quando alguém usa as mãos ou a boca como vaso, ou quando um homem ou mulher metem o dedo em lugar do membro no vaso do outro, dos quais atos em que milita

\footnotetext{
23 SINISTRARI D’AMENO, Ludovico Maria. De sodomia tractatus in quo exponitur doctrina nova de Sodomia foeminarum a Tribadismo distincta. Estratto della sezione X, parr. 256-268 dell'opera De delictis et poenis, Roma, 1754.

${ }^{24}$ Sousa (1735-1749); Ribas ([2014]).
} 
a mesma razão nunca conheceu o Santo Oficio e são havidos por molices e que parece que os breves apostólicos foram somente pedidos e concedidos para a dita propriíssima espécie de sodomia e somente nela se tem praticado (HESPANHA, 2010).

A omissão da referência à língua como instrumento deleitoso de penetração, além da mão e dos dedos, explica-se talvez menos pelo desconhecimento por parte dos castos Inquisidores de sua utilização por parte das tríbades, do que por vergonhoso pundonor. Quando, nesta mesma quadra, os Inquisidores de Lisboa depararam-se com um sacerdote cujo maior deleite com seus variegados parceiros consistia na felação, discutem se a sodomia per os (sodomia pela boca) era ou não perfeita sodomia. Concluem pela negativa, apesar de considerá-la "invenção diabólica". ${ }^{25}$ Não encontramos nas descrições das performances eróticas das denunciadas e/ou lésbicas processadas, nenhuma referência ao sexo oral. A raridade do banho e desleixo da higiene íntima nos séculos pretéritos talvez causasse asco e afastasse nossas antepassadas desta modalidade de prazer oro genital (BURG, 1984, p. 136).

O quarto e último a opinar se as somitigarias entre mulheres deviam ou não ser tratadas pelo Santo Ofício como propriíssima sodomia foi o Deputado D. Veríssimo de Lancastro, portador do mais excelso curriculum e também o mais lesbofóbico desta plêiade de altos dignitários do clero lusitano: lisboeta batizado na freguesia de Santos, doutor em cânones pela Universidade de Coimbra, cônego e tesoureiro mor da sé de Évora, deputado e promotor do Santo Oficio de Évora desde 1644, nomeado bispo de Lamego, arcebispo e senhor de Braga, primaz de Espanha, inquisidor geral em 1677, membro do conselho geral e cardeal presbítero (SILVA, 1723). Seu parecer é curto e grosso:

\footnotetext{
Pareceu que os tais atos ou sejam cometidos medio instrumento (por meio de instrumento) ou sem ele, pertencem ao conhecimento do Santo Ofício, por uns e outros serem própria e verdadeira sodomia e como tais compreendidos na generalidade dos ditos breves apostólicos. E a todos pareceu que se o Santo Oficio até agora não tomou conhecimento de semelhantes casos, vindo-se-lhe denunciar, o não podem tomar de novo, porquanto nestes termos a dita prática e observância de tanto tempo tem interpretado os ditos breves e provisões não compreenderem os ditos atos da proposta e que a dúvida dela era digna de se consultar a Sé Apostólica.
}

Como se vê, esse é o mais radical a intolerante dos oficiais da Inquisição: para ele, qualquer interação erótica entre mulheres constituía crime do conhecimento do Santo Ofício, apesar de transferir ao Papa a decisão final de como proceder contra tais delinquentes.

Aos 22 de março de 1646, assinam todos os inquisidores o dito parecer, que vem seguido da

[...] cópia do assento que se tomou no Conselho Geral sobre o procedimento das mulheres sodomitas umas com as outras. Sendo vistos pelo Conselho Geral a Carta dos Inquisidores da Índia, de 28/12/1644 e 18/1/1645, e a que avisa no \44 sob o procedimento contra as mulheres que cometem o crime de sodomia umas com as outras tendo atos sodomíticos consumados dentro do vaso, sendo íncubas e súcubas, agindo como homem com instrumento ou sem ele, e duvidando-se se podia e devia o Santo Ofício tomar conhecimento deste crime, manda o $\mathrm{Ilm}^{\circ}$ e $\mathrm{Revd}^{\circ}$ Inquisidor Geral D. Francisco Castro consultar as inquisições sobre a matéria e vistos seus pareceres, em presença da S.Ilma em 27/3/1646, se resolveu por todos os votos que

25 ANTT, TSO, IL, Proc. 6587 (Padre Santos Almeida, 1644). 
sendo a matéria duvidosa e não se havendo praticado até agora naquele crime os Breves Apostólicos, não devia o Santo Ofício tomar conhecimento dele enquanto não houvesse nova declaração da Sé Apostólica, de que se faz este assento que assinam os Srs. Conselheiros que se achavam presentes, cuja cópia sua $\mathrm{Ilm}^{\mathrm{a}}$ mandou que se remetesse às Inquisições para nesta conformidade procederem." Assinam: Diogo Velho, Pedro da Silva de Faria, Sebastião Cesar de Menezes, Francisco Cardoso de Torneo, Pantalião Alvares Pacheco. ${ }^{26}$

Como a Santa Sé nunca se manifestou sobre essa melindrosa matéria, para felicidade das lésbicas, ficou o dito pelo não dito, lembrando que por essa mesma época, o então Papa Alexandre VII manifestava inegável tolerância ao amor entre mulheres, tanto que acolheu com todas as pompas, em Roma, a recém-convertida ex-Rainha Cristina da Suécia, cujos amores lésbicos causaram grandes escândalos na época. Hoje bela placa sepulcral dessa lésbica vip encontra-se na Basílica de São Pedro, no Vaticano, com o epitáfio: Christina Regina Vandalorum. ${ }^{27}$

\section{A BIBLIOGRAFIA DOS INQUISIDORES}

Para referendar suas opiniões sobre o homoerotismo lésbico, citam os Inquisidores uma lista de 16 obras de teólogos e juristas canônicos que trataram do tema da luxúria entre mulheres, segundo eles advogando a fogueira às rés inculpadas na prática da sodomia faeminarum. Bibliografia cuja identificação do nome dos autores e suas obras oferece enormes dificuldades, algumas ainda sem solução.

Como era praxe, sobretudo depois da popularização da imprensa, os sobrenomes dos autores citados e das obras referidas, com o respectivo capítulo, eram sumariamente abreviados numa ou nas duas margens laterais da folha do livro, e não no rodapé, como praticado contemporaneamente. Assim, como as margens são estreitas, tais indicações bibliográficas eram franciscanamente abreviadas, de forma mais ou menos padronizada, tornando muitas vezes sua identificação extremamente dificultosa para os não iniciados. Muitas de tais abreviações antigas são de dificílima solução, mesmo lançando mão dos fantásticos recursos de pesquisa disponibilizados pelo bem-aventurado Google. Dos 16 autores citados pelos inquisidores, após pesquisar os catálogos das principais bibliotecas internacionais, conseguimos identificar nove obras, restando, portanto, ainda, sete incógnitas, esperando que algum leitor nos comunique caso consiga resolver essa charada bibliográfica.

Autores e obras, tal qual foram citadas ipsis litteris pelos inquisidores no parecer sobre a consulta da Inquisição de Goa:

1. Ansald. de Jurisdicte. 4.p. $\mathrm{tt}^{\mathrm{o}} 5$ cap. $1 \mathrm{n}^{\mathrm{o}} 20$

2. Guazzin. de Fens. 4 cap. 6 n 11

3. Menoch. de Arbitr. Casu. 286 nº 36

4. Fusch. de Delictis carnis. q. 148 n $^{\circ} 40$ et ss.

26 (\$100-101), fl. 713-719.

${ }^{27}$ QUEEN Christina of Sweden. Lesbian News, May 1999, v. 24, Issue 10, p. 52. 
5. Sanches. de Matrim. Lib. 10, disp. 4 n 5

6. Bordon. resol. $48 \mathrm{n}^{\circ} 10$

7. Bonac. de Matrim q. 4 punct. $11, \mathrm{n}^{\circ} 5 \$ 3^{\circ}$

8. Basco. Verbo Luxuria, $n^{\circ} 21$

9. Cordero. de Estatu Eccles. p.1, tract.11, q. 16

10. Vela. de Poenis. cap. 33 no 4

11. Marchino. de Sacramentis Ordinis. tractat. 1, p.8, cap. 4 n 5

12. Saa. Luxuria. $n^{\circ} 5$

13. Bertrand. Tract. 16 q.10 art.2

14. $\mathrm{Ven}^{\circ}$. Petes $1^{\circ}$

15. Dian. p. 7 tract. 12

16. Res.13

A seguir, apresentamos a referência bibliográfica completa dos nove autores citados que conseguimos identificar, citando-se sempre a data da primeira edição da obra no caso de ter sido estampada em mais edições, incluindo as datas de nascimento e morte dos autores quando localizadas:

1. ANSALDI, Francesco (Sec. 17) De jurisdictione tractatus in V partes divisus. Lugduni (Lion), apud G. Boissat et L. Anisson, 1643, 564 p.

2. GUAZZINO, Sebastiano (Sec.16-17) De Confiscatione bonorum, privilegiis ac praescriptionibus fisci contra delinquentes et bonorum in ejus fraudem alienatorum revocatione tractatus. Francofurti (Frankfurt), apud J. Bringeri, 1614, 327p.

3. MENOCHIO, Jacopo (1532-1607). De Arbitrariis judicum quaestionibus et causis. Coloniae Agrippinae (Colônia), apud F. Gymnicus, 1628, 755 p.

4. FARINACCIO, Prospero (1554-1618). Praxis et theoricae criminalis amplissimae pars quarta. Lungduni, (Lion), apud Iacobi Cardon, 1631, 724 p.

5. SÁNCHEZ, Tomás (1550-1610). Disputationunm de sancto matrimonii sacramento. Antverpiae (Antuérpia), apud M. Nutieux, 1607, 1239 p.

6. BONACINA, Martino. (1585-1631) Opera omnia. Siue tractatio absolutissima omnium conscentice casuum, \& multorum ad forum externum attinentium. Tomus primus complectens tractatus de sacramentis, de matrimonio, de censuris, de honoris canonici, \& tractationes varias.Venetiis, (Veneza), apud Georgium Valentinum, 1628, 770 p.

7. VELA Y ACUÑA, Juan (Sec.XVI) Tractatus de poenis delictorum. Salmanticae (Salamanca), apud Martini Perez Bibliopolae, 1596, 199 p.

8. MARCHINI, FILIBERTO (1586-1636). De Sacramento ordinis. Lugduni (Lion), apud G. Boissat et Sociorum, 1638, 467 p.

9. DIANA, Antonino. (1585-1663). Resolutionum moralium pars tertia in qua selectiores casus conscientiae sub his tractatibus explicantur. Antuerpia, apud Petrum Verges, 1633, 488 p. 
Destas obras, a mais antiga data de 1596, do jurista espanhol Vela y Acuña; as demais tiveram sua primeira edição entre 1607-1643; a mais moderna, do jurisconsulto italiano Francesco Ansaldi, publicada três anos antes da consulta da Inquisição de Goa (1646), que redundou nessa discussão teológica, o que nos permite concluir que os inquisidores dispunham de bibliografia bastante atualizada. Dos nove autores identificados, sete são italianos, dois espanhóis. Nenhum da Lusitânia, terra pobre de juristas e teólogos moralistas. Seis são sacerdotes: Bonnacia é Oblato; Marchino, Barnabita; Ansaldi, Mínimo; Sanchez, Jesuíta; Diana, Cônego Regular. Os quatro restantes são juristas, criminalistas e jurisconsultos: Menochio, Farinaccio, Guazzino e Vela y Acuña.

Todas as obras foram escritas em latim, então língua universal, usada com mais frequência sobretudo em estudos tratando de temas melindrosos da moral sexual e, ainda mais, ao se debruçar sobre os pecados contra naturam, assuntos reservados apenas a adultos capacitados na língua latina. Obras volumosas, algumas compondo coleção de tratados com até uma dezena de volumes; a mais resumida, Tractatus de poenis delictorum, com 199 páginas; diversos livros ultrapassam 700 páginas. A mais robusta é do célebre casuísta da Companhia de Jesus, Thomas Sanchez, com 1239 páginas, obra que chegou a ser incluída no Index Librorum Probibitorum, acusada de excessiva tolerância às interdições sexuais estipuladas pela teologia moral escolástica, heresia denominada laxismo. ${ }^{28}$

Como era usual naquela época, vários destes compêndios, além de exibir na capa bela gravura sacra, disponibilizam ao leitor minuciosos índices - por autores, nomes, temas e lugares citados, facilitando sobremodo a pesquisa.

Resta a dúvida se os quatro inquisidores e três deputados que emitiram os pareceres acima citados, mencionando 16 autores como supostos defensores da punição da sodomia faeminarum como crime propriíssimo - obras usadas, portanto, como substrato para a qualificação de suas decisões - se, de fato, tais manuais foram consultados no original ou se tê-los-iam citado a partir de apenas uma ou duas obras de onde retiraram as tais indicações bibliográficas. Infelizmente, a Torre do Tombo só informa a existência de uma obra manuscrita na Livraria do Santo Ofício onde consta a transcrição seletiva notadamente de um jurista: Compêndio do Tratado de Heresia de Prospero Farinacii utilizado pelo Santo Ofício datado de 1618, com 646 páginas (149 em branco):

Contém citações, em latim, principalmente, das obras de Farinacii, mas também de obras de autores estrangeiros e portugueses, com a finalidade de uniformizar a jurisprudência nas decisões que os inquisidores, juízes, promotores deveriam tomar. Inclui citações de direito inquisitorial, da instituição, de normas de procedimento e prática em relação ao crime de heresia e de julgamento. Contém ainda referências bibliográficas que foram acrescentadas às citações, dos autores António Gomes, Rodrigo Henriques, ou copiadas do Caderno das Conservatórias, entre outros. ${ }^{29}$

\footnotetext{
${ }^{28}$ Sotomaior (1667).

${ }^{29}$ ANTT, TSO, IL, 019, livro 0078. Agradeço a indicação dessa obra à historiadora Dra. Grayce Mayre Bonfim Souza (UESB), de quem tive o prazer de ser orientador em seu doutorado, na UFBA, sobre os comissários do Santo Ofício da Bahia.
} 
No índice manuscrito, à primeira página desse volume, consta a indicação "Tomo IV, De delictis carnis".

Assim sendo, como não se conhece a lista das eventuais obras impressas existentes na Livraria do Tribunal do Santo Ofício de Lisboa, nem das bibliotecas particulares dos Inquisidores, conjecturamos que talvez tenham copiado tais fontes bibliográficas a partir somente do citado Compendio, de Farinacii, ou, verbi gratia, de apenas um livro, como o De Sacramento ordinis, de Filisberto Marchini, cônego barnabita de Novara, onde, apenas no capítulo consagrado à luxuria feminina, são citados 40 autores, cinco dos quais constam entre os 16 referidos pelos inquisidores. Ou se apropriaram das citações a partir de Ansaldi, De jurisdictione tractatus, no parágrafo relativo ao homoerotismo feminino, onde são citados sete autores para abalizar seu parecer sobre sodomia faeminarum:

Faemina agens ut vir in aliam patientem faeminam sodomiam committere dicitur (Mulher agindo como homem com um mulher paciente comete sodomia). Matian.Socin., Angel.Atetin., Iacob.Menoch., Pet'r.Caball., Farinac.; Nicol.Boer. Quod declara procedere non quando mulier se corrumpit cum alia faemina sola fricatione sed quando agit aliquo instrumento materiali lígneo, aut vítreo (No que se declara proceder quando utiliza outro instrumento material lineo ou vitreo). Clar., Iacob.Menoch.

Para o barnabita Marchino, a mulher que usa instrumento para penetrar a parceira comete o crime formal de sodomia. O autor escora-se em seis autores, além do Divino Santo Tomas de Aquino, no sempre referido Farinaccio:

Si mulier cognoseat aliam mulierem in vase debito, seu naturali, sed medio instrumento, ad gerenationem prorsus inepto, illam criminem sodomiticum propriè committere et incidere in poenas reservationis et aliarum, de quibus infra, dummodo semen unius in alterius vas naturale decideret. Ratio est: quia tale delictum est coitus duorum eiujusdem sexus, non servata ratione et instrumento a natura praescrito. Sic docent S.Thom., Grassius, Sanchez. Quinimo has mulieres ordinaria mortis poena in foro exteriori puniri tradunt Antonius Gomezius, Julius Clarus, Prosper Farinacius. ${ }^{30}$

Defende, outrossim, opinião benevolente vis a vis os homófilos discretos: "Não se deve condenar sodomitas ocultos mas somente os notórios cuja notoriedade não se pode ocultar na cidade onde vive...” (\$6 fl.131)

Não obstante tal deliberação, protelando sine die a criminalização do lesbianismo, até que a Sé Apostólica se manifestasse, um século depois, em 1741 é presa a lésbica mais ousada a cair nas malhas do Santo Ofício de Portugal: Maria Duran, 31 anos, natural da Catalunha, noviça no Convento das dominicanas de Nossa Senhora do Paraíso de Évora, acusada por diversas cúmplices de ter um pênis secreto. Em seu processo lê-se:

\footnotetext{
30 "Se a mulher fornicar com outra mulher no vaso devido, ou natural, mas através de instrumento inadequado para a procriação, comete propriamente o crime sodomítico e incide nas penas reservadas e outras mais, como descrito abaixo, em que a semente do homem cai no vaso natural posterior de outro. A razão é: tal delito é o coito entre duas pessoas do mesmo sexo não utilizando o instrumento prescrito pela natureza. Assim ensinam dizem SantoThomas, Grassius, Sanchez. Na verdade, essas mulheres devem ser punidas com pena de morte in foro exteriori (pela autoridade civil), de acordo com Antonius Gomezius, Julius Clarus, Prosper Farinacius”. Agradeço ao antropólogo Dr. Robson Cruz, da Universidade da Integração Internacional da Lusofonia Afro-Brasileira, por me ajudar na tradução desse parágrafo.
} 
Constou na mesa do Santo Ofício que sendo a ré propriamente mulher sem distintivo algum do sexo masculino, usava dele como se fosse homem, tendo cópula com muitas mulheres a quem pedia e recomendava lhe guardassem segredo sob pena de as matar ou mandar matar. A muitas declarou que para atrair mulheres para satisfação dos seus torpes apetites lhe bastava dizer algumas palavras, olhar para elas e tocá-las por que logo as rendia, fossem velhas ou moças e jactava-se de que tinha rendido muitas, e que de uma solteira tivera um filho... Declarou ter feito várias peregrinações por alguns reinos distantes, que nestes usava e também neste, umas vezes com traje de mulher, outras no de homem, com mais conveniências lhe parecia para passar a vida, porque fora tratante e soldado de cavalo no reino de Aragão e Catalunha. Declarou mais que por sua grande miséria e propensão que tinha para a luxúria, cometera muitos atos torpes e desonestos com várias mulheres fingindo-se homem sem o ser.

Sua sentença, lida no auto de fé de 21 de junho de 1744, exatamente um século após a consulta da Inquisição de Goa sobre a sodomia faeminarum, incluiu abjuração de leve suspeita na fé, por ter feito pacto com o demônio, foi açoitada publicamente pelas ruas de Lisboa, obrigada a penas e penitências espirituais, degredada para fora do reino, ficando impedida de a ele voltar. ${ }^{31}$

Hoje provavelmente essa mulher-macho seria identificada como um homem-trans, que juntamente com as mulheres-trans, por resolução unânime do Supremo Tribunal Federal do Brasil, a partir de 2018, têm o direito de mudar seu registro civil, adequando seu sexo e nome à identidade de gênero autodeclarada.

Quanto à Santa Sé, fiel ao anacrônico Catecismo de Trento (1566), embora continue a classificar o homoerotismo como pecado mortal, o papa Francisco declarou em alto e bom som ao retornar ao Vaticano após sua visita ao Brasil (2013): "Quem somos nós para julgar os gays!"

Roma locuta, disputa finita!

\section{FONTES}

Arquivo Nacional da Torre do Tombo, Manuscritos da Livraria, 1358-1359, Tribunale Perfectum (sive) Commentaria ad RegimemSencti Officii Regni Portugaliae.

ANT'T, Tribunal do Santo Ofíio (TSO), Conselho Geral (CG), 035, 0123

Arquivo Nacional da Torre do Tombo (ANTT), Tribunal do Santo Ofício (TSO), Inquisição de Lisboa (IL), Cadernos do Promotor, n. 58, 1.464-475

ANTT, TSO, IL 019, 0078.

ANTT, TSO, IL, Proc. 557.

ANTT, TSO, IL, Proc. 1267.

ANTT, TSO, IL, Proc. 1942 (Catarina Ligeira).

ANTT, TSO, IL, Proc. 3185.

31 ANTT, TSO, IL, Proc. 9230. Disponível em: http://digitarq.arquivos.pt/viewer?id=2309369: Soyer (2012). 
ANTT, TSO, IL, Proc. 6587 (Padre Santos Almeida, 1644).

ANTT, TSO, IL, Proc. 9230. Disponível em: http://digitarq.arquivos.pt/viewer?id=2309369.

ANTT, TSO, IL, Proc. 11860 (Maria Machada).

ANTT, TSO, IL, Proc.13.787. Disponível em: https://digitarq.arquivos.pt/details?id=4510000;

Biblioteca Nacional de Lisboa (BNL), Correspondência da Inquisição de Évora e Goa ao Conselho Geral, 16441646, fl.361-364.

BNL, Seção de Reservados, Códice 869, fl. 361-364.

Cancioneiro Português da Vaticana, Edição crítica por Teófilo Braga. Lisboa, Imprensa Nacional, 1878, canção 1115.

Ordenaçoes do senhor Rei D, Manuel. Livro V. Coimbra, 1797.

Ordenações e Leis do Reino de Portugal recopiladas por mandado del Rei D. Filipe o Primeiro. Livro V. Coimbra, 1789.

Regimento do Santo Oficio da Inquisiżão dos Reinos de Portugal, ordenado por mandado do Ilustríssimo e Reverendíssimo Senhor Bispo D. Francisco de Castro, Titulo XXV, livro III,. Lisboa, 1640.

Regimento do Santo Oficio, Título XXII, 1774.

Tribunalem Perfectum, sive Comentaria ad regimem Sancti Officii Regni Portugaliae. Manuscritos da Livraria, Joannis Alvares Soares, Inquisidor de Lisboa, 2 tomos, Tomo I, Gloss. 38, Contra os culpados no crime de sodomia, 2 dubitatio.

\section{REFERÊNCIAS}

ABREU, A. A. Sobre formas de comportamento sexual em Portugal no século XVI. Separata do Boletim cultural do ginásio clube Vilacondense, n. 36, p. 1-42, 1980.

AguiAR, A. A. Evolução da Pederastia e do Lesbismo na Europa. Separata do Arquivo da Universidade de Lisboa, v. XI, p. 335-620, 1926.

BELLINI, L. A coisa obscura: mulher, sodomia e Inquisição no Brasil colonial. São Paulo: Brasiliense, 1989.

BRAGA, P. D. Dois casos de homossexualidade feminina no Portugal quinhentista. Vértice, v. 72, p. $87-$ 90, 1996.

BRAGA, P. D. Filhas de Safo. Uma história da homossexualidade feminina em Portugal (Séculos XIIIXX). Lisboa: Texto, 2011.

BRANDÃO, A. M. Da sodomita à lésbica: o género nas representações do homo-erotismo feminino. Análise Social, Lisboa, n. 195, 2010.

BROWN, J. C. Atos Impuros: a Vida de uma Freira Lésbica na Itália da Renascença. São Paulo: Brasiliense, 1987.

BURG, B. R. Sodomy and the Pirate Tradition. New York: New York University Press, 1984. 
CAPRIO, F. S. Homossexualidade feminina. São Paulo: Ibrasa, 1968.

CASTRO, R. De universa mulierum Medicina. Haburgo, Officina Frobeniana, 1603.

COLOMBO, R. Realdi Columbi Cremonensis, in almo Gymasio Romano Anatomici celeberrimi, De re anatomica, libri XV. Venetiis: Ex Typographia Nicolai Beuilacquae, 1559.

CORREIA, P. Novas Cartas Jesuíticas. São Paulo: Ed. Nacional, 1940.

DE GRAAF, R. De virorum organis generationi inservientibus : De clysteribus et De usu siphonis in anatomia. Lugd. Batav [Leyden]; Roterod[Rotterdam]: Ex officina Hackiana, 1668.

GANDAVO, P. M. História da Provincia Santa Cruze Tratado da Terra do Brasil. São Paulo: Obelisco, 1964.

HESPANHA, A. M. Direito moderno e intertextualidade. Direito próprio e Direito comum em "De Jure Lusitano" (1645), de Mateus Homem Leitão. Coimbra: Imprensa da Universidade de Coimbra, 2010.

MATOS, G. Obras Completas. Ed. de James Amado. Salvador: Janaina, 1969.

MONTEIRO, A. C. O amor sáfico e socrático. Lisboa: Instituto de Medicina Legal de Lisboa, 1922.

MORAIS, C. A. (1632-1693). Pedatura Lusitana: Nobiliário de famílias de Portugal. Porto: Livraria Fernando Machado, 1943-1948.

MOTT, L. Da fogueira ao fogo do inferno: a descriminalização do lesbianismo em Portugal, 1646. Comunicação apresentada na International Conference on Lesbian and Gay History. Toronto: Canadá, jul. 1985.

MOT'T, L. Desventuras de um degredado sodomita na Bahia seiscentista. In: MOT'T, L. Babia: Inquisiçãa e sociedade. Salvador: EDUFBA, 2010.

MOTT, L. Dicionário Biográfico dos Homossexuais da Babia (Séculos XVI-XIX). Salvador: Ed. Grupo Gay da Bahia, 1999.

MOTT, L. Florença Dias Pereira e Maria Soares: esposas de dois sodomitas no Brasil Colonial: vítimas ou vilãs?. In: NEVES, G. P. das; SANTOS, G. S. dos; VAINFAS, R. (org.). Retratos do Império. Trajetórias Individuais no mundo português nos séculos XVI a XIX. Niterói: Eduff, 2006.

MOTT, L. O Lesbianismo no Brasil. Porto Alegre: Mercado Aberto, 1987.

MOTT, L. Pagode Português: a subcultura gay em Portugal nos tempos da Inquisição. Ciência e Cultura, São Paulo, v. 40, p. 120-139, fev. 1988.

NAPOLITANO, M. N. O discurso médico sobre os vícios femininos na sociedade carioca oitocentista. Dissertação (Mestrado em História) - Faculdade de História, Direito e Serviço Social, Universidade do Estado de São Paulo, Franca, 2004a.

NAPOLITANO, M. N. A Sodomia Feminina na Primeira Visitação do Santo Ofício ao Brasil. História Hoje, São Paulo, n.3, p. 1-11, 2004b.

PACHECO, F. Um Dicionário inédito da língua indígena. Revista da Academia Brasileira de Letras, Rio de Janeiro, Ano 26, n. 153, 1934. 
PARK, K. The Rediscovery of the Clitoris: French Medicine and the Tribade (1570-1620). In: MAZZIO, C. \& HILLMAN, D. (ed.), The body in parts. Fantasies of corporeality in early modern Europe. New York; London: Routledge, 1997. p. 171-193.

PAYER, P. J. Sex and the Penintentials. The Development of a Sexual Code, 550-1150. Toronto: University of Toronto Press, 1986.

PERES, F. da R. Gregório de Matos e a Inquisição. Salvador, UFBA/Centro de Estudos Baianos, 1987.

QUEEN Christina of Sweden. Lesbian News, v. 24, Issue 10, p. 52, May 1999.

REPERTÓRIO Geral ou Índice Alfabético das Leis Extravagantes do Reino de Portugal. Coimbra: Real Imprensa da Universidade, 1819.

RIBAS, M. S. M. O Governo do Tribunal do Santo Ofício no Tempo de D. Pedro de Lencastre (1671 -1673), Boletim do Arquivo da Universidade de Coimbra, v. XXVII, p. 341-373, [2014].

SILVA, M. T. Coleçam dos documentos e memórias da Academia Real da Historia Portuguesa. Lisboa: Officina de Pascoal da Sylva, 1723.

SINISTRARI D'AMENO, L. M. De sodomia tractatus in quo exponitur doctrina nova de Sodomia foeminarum a Tribadismo distincta. Estratto della sezione X, parr. 256-268 dell'opera De delictis et poenis. Roma, 1754.

SOTOMAIOR, A. Index librorum probibitorum et expurgandorum nonissimus. Pro catbolicis Hispaniarum regnis Philippi 4. Madrid: Tip.Didaci Dias, 1667.

SOUSA, A. C. de, C. R. (1674-1759). História genealógica da Casa Real Portugueza: desde a sua origem até o presente. Lisboa Occidental: Officina de Joseph Antonio da Sylva, 1735-1749.

SOYER, F. Ambiguous Gender in Early Modern Spain and Portugal: Inquisitors, Doctors and the Transgression of Gender Norms. Leiden: Brill, 2012.

VAINFAS, R. Sodomia, mulheres e inquisição: notas sobre sexualidade e Homossexualismo feminino no Brasil colonial. Anais do Museu Paulista. São Paulo, v. 35, p. 233-254, 10 dez. 1987

VELASCO, S. Lesbians in Early Modern Spain. Vanderbilt University Press, 2011.

Data de submissão: 03/07/2021

Data de aprovação: 13/07/2021 